\title{
Synthetic Strategy and Structure Characterization of a New [1,3]Thiazolo[3,2-b][1,2,4]Triazolium Cationic Surfactant
}

\author{
Maksym Fizer 1,*iD, Mikhailo Slivka ${ }^{2}$ (D) Oksana Fizer $^{3}$ (D) \\ 1 Department of Organic Chemistry, Faculty of Chemistry, Uzhhorod National University, Fedinets', Str. 53/1, 88000, \\ Uzhhorod, Ukraine; max.fizer@uzhnu.edu.ua (M.F.); mikhailo.slivka@uzhnu.edu.ua (M.S.); oksana.fizer@uzhnu.edu.ua \\ (O.F.); \\ * Correspondence: max.fizer@uzhnu.edu.ua; (M.F.);
}

Scopus Author ID 55823743600

Received: 20.01.2021; Revised: 21.02.2021; Accepted: 24.02.2021; Published: 1.03.2021

\begin{abstract}
Here, we present a synthetic strategy to access a new [1,3]thiazolo[3,2-b][1,2,4]triazoliumbased cationic surfactant via the use of proton-induced heterocyclization method for quaternization of a nitrogen atom. The two-step synthesis of 2-heptyl-6,6-dimethyl-3-phenyl-5,6-dihydro-3H[1,3]thiazolo[3,2-b][1,2,4]triazol-7-ium perchlorate is described in details. The analysis of NMR spectra unequivocally proved the formation of the 1,3-thiazolinium ring upon cyclization reaction. PM7 semiempirical calculations testify to the similar electronic structure of the newly synthesized surfactant cation and 1-heptylpyridinium cation.
\end{abstract}

Keywords: 1,2,4-triazole; alkylation; cyclization; surfactant; NMR; cation; PM7; semiempirical.

(C) 2021 by the authors. This article is an open-access article distributed under the terms and conditions of the Creative Commons Attribution (CC BY) license (https://creativecommons.org/licenses/by/4.0/).

\section{Introduction}

The development of quaternary ammonium surfactants' chemistry is dictated by their wide usage [1-4], for example, anti-corrosion [5-9] and antibacterial activity [10-16]. It must also be mentioned the importance of quaternary ammonium compounds during the COVID-19 pandemic [17-20]. That is why the development of new cationic surfactants is still an actual task in modern organic chemistry. One of the most popular heterocyclic cationic surfactants with antibacterial activity is cetylpyridinium chloride [21, 22]. However, this substance has a raw of drawbacks due to numerous harmful effects [23]. Consequently, the development of less toxic compounds is in priority of synthetic chemistry. In one of our previous works, we have estimated the toxicity of [1,3]thiazolo[3,2-b][1,2,4]triazolium cationic surfactants, and it has been found that the toxicity of this class of compounds is less than the toxicity of commonly used quaternary ammonium surfactants [24]. Thus the present work proposed a synthetic strategy for the obtaining of the [1,3]thiazolo[3,2-b][1,2,4]triazolium cationic species.

Based on our previous findings [25-28], we propose the proton-induced electrophilic cyclization reaction as a general synthetic approach to [1,3]thiazolo[3,2-b][1,2,4]triazolium cations. Taking into account the appropriateness of the starting 1,2,4-triazole-3-thion system for the introduction of various substituents, the described synthetic route can be used for obtaining a novel family of cationic surfactants and ionic liquids based on the $[1,3]$ thiazolo[3,2b] $[1,2,4]$ triazolium system. It must be clarified that the positively charged [1,3]thiazolo[3,2b] $[1,2,4]$ triazolium system acts as a "polar hydrophilic head". In contrast, a long alkyl chain, 
which can be easily introduced to the desired compound, serves as a "non-polar hydrophobic tail". The synthetic procedure for one representative of this type of surfactants, the perchlorate salt of 2-heptyl-6,6-dimethyl-3-phenyl-5,6-dihydro-3H-[1,3]thiazolo[3,2-b][1,2,4]triazol-7ium, is described in the "Materials and Methods" section in details, whereas the analysis of its structure based on NMR studies and quantum chemical calculations discussed in the "Results and Discussion" section.

\section{Materials and Methods}

All reagents and solvents were purchased from Sigma-Aldrich, Acros Organics, or Sfera Sim companies and were used without additional purification. Shimadzu IRTracer-100 spectrometer was used for recording Fourier-transform infrared spectra (FTIR). NMR spectra in deuterated dimethyl sulfoxide (DMSO-d6) solutions were recorded on a Varian Mercury400 instrument, and tetramethylsilane was used as an internal standard. Quantum chemical calculations were performed on the dual-processor 24 threads workstation with 64 GB of RAM. MOPAC2016 software [29] was used for semiempirical PM7 calculations [30]. Visualization of molecular structures and molecular electrostatic potential (MESP) was performed with the Jmol program [31].

5-Heptyl-4-phenyl-2,4-dihydro-3H-1,2,4-triazole-3-thione (1) was synthesized starting from octanoic acid hydrazide and phenyl isothiocyanate, which form N1-octanoyl- N4-phenylthiosemicarbazide via the known method [32]. Further reflux in $3 \mathrm{M}$ sodium hydroxide solution for 1 hour causes intramolecular cyclization and formation of the 1,2,4-triazole-3-thiol sodium salt. Next neutralization with $50 \%$ acetic acid solution leads to the precipitation of the target thione 1. The yield is $84 \%$. FT-IR $\left(\mathrm{V}_{\max }, \mathrm{cm}^{-1}\right)$ 2960-2850, 1570, 1500, 1410. ${ }^{1} \mathrm{H}$ NMR (400 MHz, DMSO-d6) $\delta$ (ppm): 13.67 (s, 1H, NH); 7.63-7.48 (m, 3H, Ph), 7.40 (d, J = 7.2 Hz, 2H, $\mathrm{Ph}), 2.41\left(\mathrm{t}, \mathrm{J}=7.4 \mathrm{~Hz}, 2 \mathrm{H}, \alpha-\mathrm{CH}_{2}\right), 1.42\left(\mathrm{~m}, 2 \mathrm{H}, \beta-\mathrm{CH}_{2}\right), 1.18-1.13\left(\mathrm{~m}, 8 \mathrm{H}, 4 \mathrm{CH}_{2}\right), 0.81$ (t, J $\left.=6.9 \mathrm{~Hz}, 3 \mathrm{H}, \mathrm{CH}_{3}\right) .{ }^{13} \mathrm{C}$ NMR $(101 \mathrm{MHz}, \mathrm{DMSO}-\mathrm{d} 6) \delta(\mathrm{ppm}): 168.1 ; 152.6 ; 134.3 ; 129.9$; $128.7 ; 31.4 ; 28.5 ; 28.5 ; 25.6 ; 22.5 ; 14.4$. The elemental analysis: found: $\mathrm{C}, 65.5 ; \mathrm{H}, 7.9 ; \mathrm{N}$, 15.2; S $11.5 \%$; calc. for $\mathrm{C}_{15} \mathrm{H}_{21} \mathrm{~N}_{3} \mathrm{~S}$ : C, $65.4 ; \mathrm{H}, 7.7 ; \mathrm{N}, 15.3 ; \mathrm{S}, 11.6 \%$.

3-Heptyl-5-[(2-methylprop-2-en-1-yl)sulfanyl]-4-phenyl-4H-1,2,4-triazole (2) was obtained via the alkylation of thione 1 , similar to the known procedure [26, 27, 33]. A $5.50 \mathrm{~g}$ $(0.02 \mathrm{~mol})$ sample of thione 1 and $0.8 \mathrm{~g}(0.02 \mathrm{~mol})$ of sodium hydroxide were dissolved in 100 $\mathrm{ml}$ of ethanol. The $2.0 \mathrm{ml}$ ( $0.02 \mathrm{~mol}$ of $97 \%$-purity) methallyl chloride was introduced, and the resulting mixture was refluxed for 1 hour. The liquid phase was decanted from the sodium chloride solid after cooling. The resulting solution was heated for evaporation to about the third of its volume. The target S-methallyl thioether was crunched from the liquor by the addition of $200 \mathrm{ml}$ of water. Most of the yellow oil thioether 2 was separated with a separatory funnel, and the remaining thioether 2 was extracted by $3 \times 30 \mathrm{ml}$ portions of chloroform. The main portion of thioether 2 was mixed with chloroform extracts, dried over calcium chloride. The solvent was evaporated under vacuum, giving a resulting material as a yellow oil in $70 \%$ yield (4.60 g). The S-methallyl thioether 2 was used without further purification. FT-IR $\left(\mathrm{V}_{\max }, \mathrm{cm}^{-1}\right) 2960$ 2850, 1500, 1430. ${ }^{1} \mathrm{H}$ NMR (400 MHz, DMSO-d6) $\delta(\mathrm{ppm}): 7.59-7.39$ (m, 5H, Ph), $4.81(\mathrm{~s}$, $\left.1 \mathrm{H},=\mathrm{CH}_{2}\right), 4.77\left(\mathrm{~s}, 1 \mathrm{H},=\mathrm{CH}_{2}\right), 3.62\left(\mathrm{~s}, 2 \mathrm{H}, \mathrm{SCH}_{2}\right) ; 2.47\left(\mathrm{t}, \mathrm{J}=7.4 \mathrm{~Hz}, 2 \mathrm{H}, \alpha-\mathrm{CH}_{2}\right), 1.65(\mathrm{~s}$, $\left.3 \mathrm{H}, \mathrm{CH}_{3}-\mathrm{C}=\right) ; 1.45\left(\mathrm{~m}, 2 \mathrm{H}, \beta-\mathrm{CH}_{2}\right) ; 1.21-1.13\left(\mathrm{~m}, 8 \mathrm{H}, 4 \mathrm{CH}_{2}\right) ; 0.81\left(\mathrm{t}, \mathrm{J}=6.9 \mathrm{~Hz}, 3 \mathrm{H}, \mathrm{CH}_{3}\right)$. ${ }^{13} \mathrm{C}$ NMR (101 MHz, DMSO-d6) $\delta$ (ppm): 156.1; 149.4; 140.7; 133.7; 130.3; 127.8; 126.1; $115.0 ; 31.4 ; 28.6 ; 28.6 ; 26.6 ; 25.0 ; 22.4 ; 21.1 ; 14.3$. The elemental analysis: found: $\mathrm{C}, 69.4 ; \mathrm{H}$, 8.5; N, 12.7; S 9.6\%; calc. for $\mathrm{C}_{19} \mathrm{H}_{27} \mathrm{~N}_{3} \mathrm{~S}: \mathrm{C}, 69.3 ; \mathrm{H}, 8.3 ; \mathrm{N}, 12.8 ; \mathrm{S} 9.7 \%$. 
2-Heptyl-6,6-dimethyl-3-phenyl-5,6-dihydro-3H-[1,3]thiazolo[3,2-b][1,2,4]triazol-7ium perchlorate (3). The S-methallyl ether $2(1.65 \mathrm{~g}, 0.005 \mathrm{~mol})$ was dissolved in $20 \mathrm{ml}$ of glacial acetic acid, and $20 \mathrm{ml}$ of $40 \%$ hydrobromic acid was added. The resulting mixture was refluxed for 2 hours, then cooled, and mixed with $50 \mathrm{ml}$ of cold water. No precipitation or cloudiness was observed. The $10 \mathrm{ml}$ of $2 \mathrm{M}$ solution of sodium perchlorate was added to the reaction mixture, resulting in perchlorate 3 . The yield is $1.63 \mathrm{~g}(76 \%)$. FT-IR $\left(V_{\max }, \mathrm{cm}^{-1}\right) 3400$, 1070, 620. ${ }^{1} \mathrm{H}$ NMR (400 MHz, DMSO-d6) $\delta$ (ppm): 7.72 (br. s, 5H, Ph); 4.19 (s, 2H, SCH 2 ); $2.70\left(\mathrm{t}, \mathrm{J}=7.2 \mathrm{~Hz}, 2 \mathrm{H}, \alpha-\mathrm{CH}_{2}\right), 1.68\left(\mathrm{~s}, 6 \mathrm{H},\left(\mathrm{CH}_{3}\right)_{2} \mathrm{C}\right) ; 1.53\left(\mathrm{~m}, 2 \mathrm{H}, \beta-\mathrm{CH}_{2}\right), 1.27-1.16(\mathrm{~m}, 8 \mathrm{H}$, $\left.4 \mathrm{CH}_{2}\right) ; 0.81(\mathrm{t}, \mathrm{J}=6.5 \mathrm{~Hz}, 1 \mathrm{H}) .{ }^{13} \mathrm{C}$ NMR $(101 \mathrm{MHz}, \mathrm{DMSO}-\mathrm{d} 6) \delta 159.7 ; 156.5 ; 131.6 ; 131.1$; $130.6 ; 126.0 ; 66.7 ; 49.8 ; 30.9 ; 27.9 ; 27.9 ; 25.2 ; 24.9 ; 24.6 ; 21.9 ; 13.9$. The elemental analysis: found: $\mathrm{C}, 53.2 ; \mathrm{H}, 6.7 ; \mathrm{N}, 9.7 ; \mathrm{S} 7.3 \%$; calc. for $\mathrm{C}_{19} \mathrm{H}_{28} \mathrm{ClN}_{3} \mathrm{O} 4 \mathrm{~S}: \mathrm{C}, 53.1 ; \mathrm{H}, 6.6 ; \mathrm{N}, 9.8 ; \mathrm{S}$ $7.5 \%$.

\section{Results and Discussion}

The proposed synthetic approach is shown in Scheme 1. Starting hydrazides A are commercially available or can be directly obtained synthetically. The reaction of hydrazines with various isothiocyanates readily produces $\mathrm{N} 1$-acyl-, $4 \mathrm{~N}$-substituted thiosemicarbazides $\mathrm{B}$. The next treatment of B with strong bases selectively leads to 1,2,4-triazole-anions $\mathrm{C}$, which can be obtained in neutral thione form $\mathrm{D}$ via the neutralization with acids. The alkylation of anionic forms $\mathrm{C}$ with alkenyl halides selectively leads to the alkenyl thioethers E. Finally, unsaturated thioethers $\mathrm{E}$ undergo intramolecular cyclization under the action of strong acids and form target [1,3]thiazolo[3,2-b][1,2,4]triazolium cations $\mathrm{F}$.

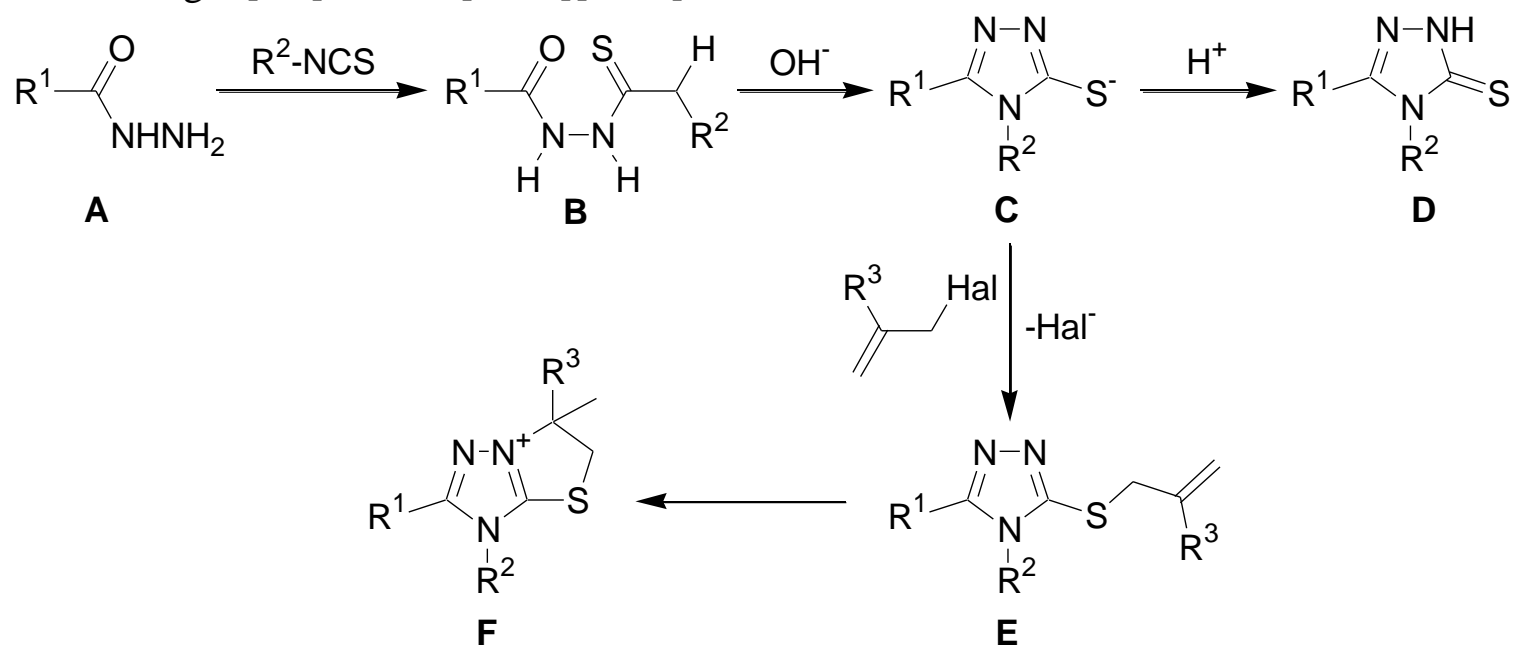

$\mathrm{R}^{1}, \mathrm{R}^{2}=$ aklyl, aralkyl, aryl, heteroaryl, heteroaralkyl

$\mathrm{R}^{3}=$ alkyl, aryl

Scheme 1. Proposed reaction approach to $[1,3]$ thiazolo[3,2-b][1,2,4]triazolium cations F.

We have to note the structural diversity of the proposed compounds. The utilization of various hydrazides at the first stage of the synthetic route gives an easy and cheap approach for modifying the $\mathrm{R}^{1}$ substituent in the $5^{\text {th }}$ position of the triazole ring. Similarly, different isothiocyanates usage allows for variating the $\mathrm{R}^{2}$ substituent in the triazole ring's $4^{\text {th }}$ position. It must be mentioned that the diversity of commercially available acids is much higher than isothiocyanates; however, applying numerous synthetic ways to isothiocyanates [26-28, 34] increases the virtual diversity of proposed 1,2,4-triazole-3-thiones $\mathrm{D}$. Definitely, the $\mathrm{R}^{3}$ substituent is not so easy to variate; in the present study, $\mathrm{R}^{3}$ substituent equals methallyl group. 
Synthesis of the above proposed [1,3]thiazolo[3,2-b][1,2,4]triazolium cationic surfactant was started from 5-heptyl-4-phenyl-2,4-dihydro-3H-1,2,4-triazole-3-thione 1 (see Scheme 2). The reaction of thione 1 with methallyl chloride was performed in sodium hydroxide ethanolic solution. Analysis of NMR spectra testifies the formation of the Smethallyl thioether 2 . Thus, the ${ }^{1} \mathrm{H}-\mathrm{NMR}$ spectrum of thione 1 contains a signal of cyclic $\mathrm{NH}$ proton at $13.67 \mathrm{ppm}$, signals of the phenyl ring in the region of 7.63-7.40 ppm, triplet of the $\alpha-$ methylene group at $2.41 \mathrm{ppm}$, and signals of the rest hydrogen atoms of the alkyl chain in the region of $1.42-1.13 \mathrm{ppm}$, and a triplet of the terminal methyl group at $0.81 \mathrm{ppm}$. Whereas, in the case of ether $2{ }^{1} \mathrm{H}-\mathrm{NMR}$ spectrum, there is no cyclic NH-proton signal, oppositely, appear signals of methallyl fragment: two singlets at 4.77 and $4.81 \mathrm{ppm}$ related to methylidene group, S-methylene group signal at $3.62 \mathrm{ppm}$, and a singlet at $1.65 \mathrm{ppm}$ related to the methyl group. The $\alpha$-methylene group signal appears as a triplet at $2.47 \mathrm{ppm}$, partially overlapping with the DMSO-d6 peak.

The analysis of ${ }^{13} \mathrm{C}-\mathrm{NMR}$ spectra of thione 1 confirms the introduction of the methallyl fragment into the molecule. Thus, the signals of triazole and phenyl carbon atoms appear in the region of 128.7-168.1 ppm. The signals of six methylene groups of the heptyl chain occur in the region of 22.5-31.4 ppm, and the peak of the terminal methyl group is located at $14.4 \mathrm{ppm}$. Whereas, in the case of thioether 2, the ${ }^{13} \mathrm{C}-\mathrm{NMR}$ spectrum also contains the peak of the methallyl group central carbon atom at $140.7 \mathrm{ppm}$, the methylidene carbon atom's peak at 115.0 ppm, and the methyl group signal at $21.1 \mathrm{ppm}$. It must be noted that the S-methylene group signal overlaps with the DMSO-d6 multiplet, which is why it cannot be appropriately identified.

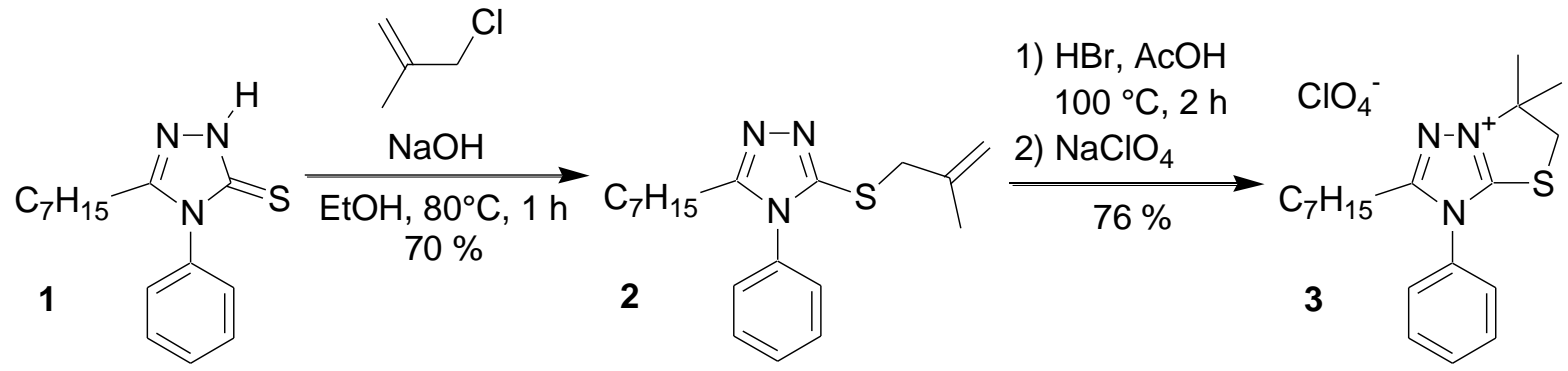

Scheme 2. Synthesis of 2-heptyl-6,6-dimethyl-3-phenyl-5,6-dihydro-3H-[1,3]thiazolo[3,2-b][1,2,4]triazol-7-ium perchlorate 3.

Proton-induced cyclization of methallyl thioether 2 was performed by the action of $40 \%$ hydrobromic acid in acetic acid under reflux for two hours. The thiazoline ring formation was unequivocally confirmed via the NMR spectral analysis (Figure 1). Thus, the ${ }^{1} \mathrm{H}-\mathrm{NMR}$ spectrum of the perchlorate 3 contains a singlet of two exocyclic methyl groups at $1.68 \mathrm{ppm}$ with a related intensity of 6 . The signal of the endocyclic methylene group appears as a singlet at $4.19 \mathrm{ppm}$. Noteworthy that the $\alpha$-methylene group triplet appears at $2.70 \mathrm{ppm}$. We assume that this downfield shift is caused by the influence of a highly electron-accepting positively charged triazolium ring. The signals of the rest of the heptyl chain hydrogen atoms appear in the region of 0.81-1.53 ppm. Interestingly, in the ${ }^{1} \mathrm{H}-\mathrm{NMR}$ spectrum of 3 , the phenyl ring hydrogen atoms' signals considerably overlapped and form one intense peak at $7.72 \mathrm{ppm}$. A broad peak at $4.40 \mathrm{ppm}$ is caused by the presence of water molecules. 


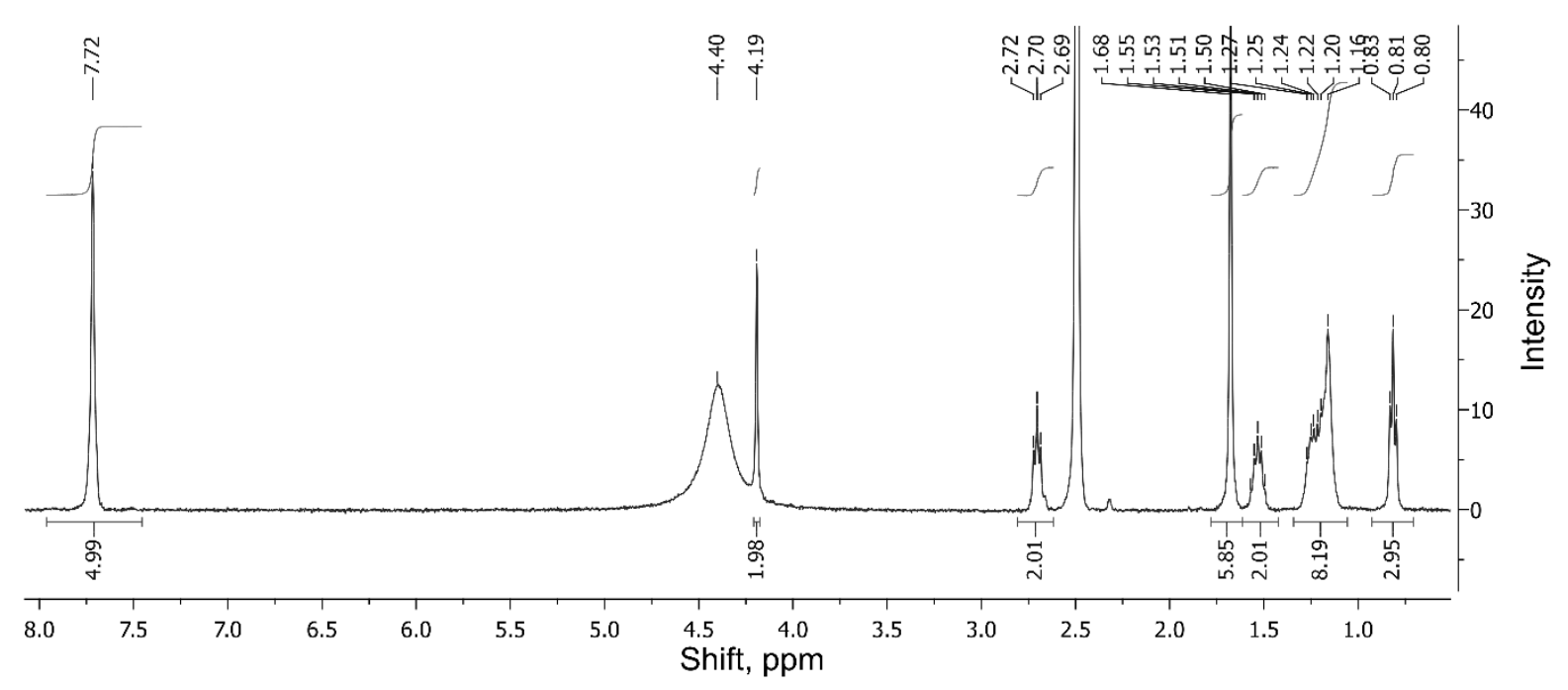

Figure 1. ${ }^{1} \mathrm{H}-\mathrm{NMR}$ spectra of 2-heptyl-6,6-dimethyl-3-phenyl-5,6-dihydro-3H-[1,3]thiazolo[3,2b] $[1,2,4]$ triazol-7-ium perchlorate 3 .

The analysis of the ${ }^{13} \mathrm{C}$-NMR spectrum testifies the formation of the thiazolinium ring also. The signal of the quaternary carbon atom appears at $66.7 \mathrm{ppm}$ (Figure 2). The intense peak at $24.6 \mathrm{ppm}$ corresponds to the two equivalent exocyclic methyl groups. The signal of the exocyclic S-methylene group appears at $49.8 \mathrm{ppm}$. It must be noticed that the peaks of the phenyl ring carbon atoms appear in a relatively narrow region of 126.0-131.6 ppm.

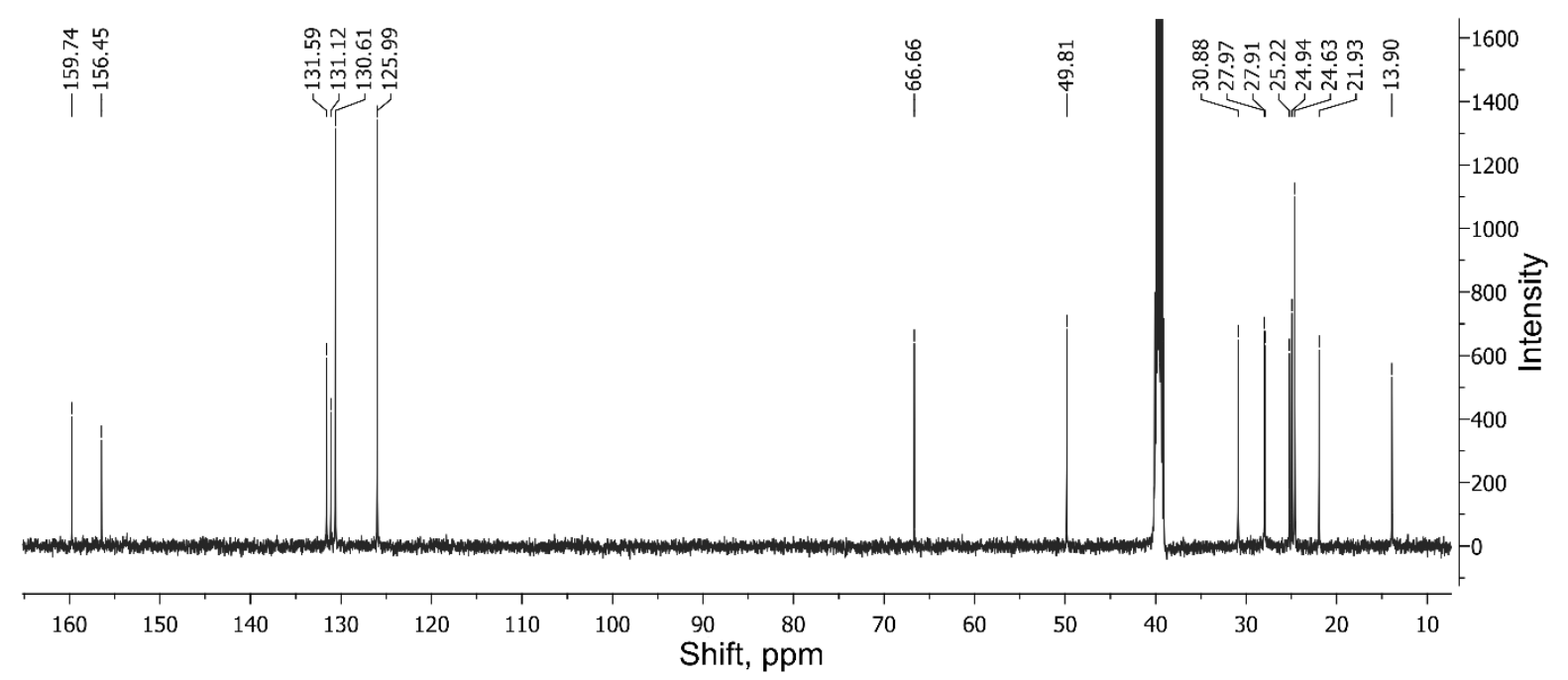

Figure 2. ${ }^{13} \mathrm{C}$-NMR spectra of 2-heptyl-6,6-dimethyl-3-phenyl-5,6-dihydro-3H-[1,3]thiazolo[3,2b] $[1,2,4]$ triazol-7-ium perchlorate 3 .

To compare the electronic structure of the synthesized 2-heptyl-6,6-dimethyl-3-phenyl5,6-dihydro-3H-[1,3]thiazolo[3,2-b][1,2,4]triazol-7-ium cation 3 with the known heterocyclic cationic surfactants, we have performed some basic quantum chemical calculations. The welldescribed cationic surfactants are cetylpyridinium salts [23]. However, for consistency, we have used 1-heptylpyridinium cation as a reference substance. The semiempirical PM7 level of theory was utilized to optimize geometric parameters and calculate atomic partial charges for cation 3 and 1-heptylpyridinium. This method is robust for modeling $\mathrm{C}, \mathrm{H}, \mathrm{N}$, and Scontaining systems $[30,35]$, and partial charges obtained with this method can be used to predict physicochemical properties [36]. MESPs of cation 3 and 1-heptylpyridinium are presented in Figure 3. Bright blue areas represent highly polar parts of the molecules, whereas red areas correspond to non-polar regions; the green areas correspond to intermediate polarity. 
It is clear that the thiazolinium ring, and to less extent, the two exocyclic methyl groups and the phenyl ring represent the "hydrophilic head," analogously to the pyridine ring of the 1heptylpyridinium cation. Nevertheless, it must be highlighted that the polarity of cation 3 is less than the polarity of 1-heptylpyridinium.

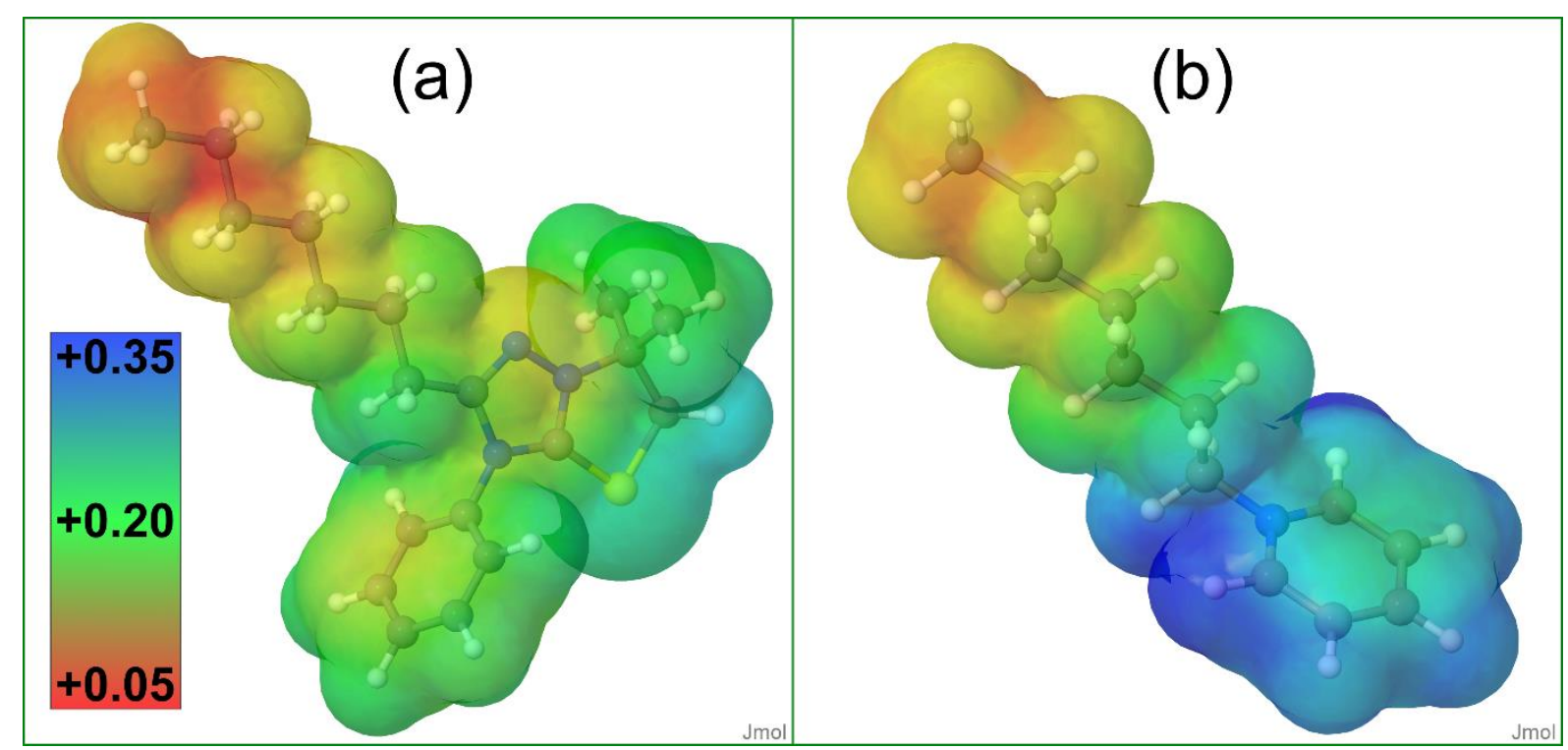

Figure 3. MESP of: (a) cation 3; (b) 1-heptylpyridinium cation. Values are given in a.u.

\section{Conclusions}

The synthesis of the new cationic surfactant 2-heptyl-6,6-dimethyl-3-phenyl-5,6dihydro-3H-[1,3]thiazolo[3,2-b][1,2,4]triazol-7-ium perchlorate was described in details. Comparing molecular electrostatic potentials of the new heterocyclic cation and 1heptylpyridinium cation testifies their electronic similarities. Moreover, these calculations have proved the assumption that the positively charged [1,3]thiazolo[3,2-b][1,2,4]triazol-7-ium system acts as a "polar hydrophilic head," and the heptyl chain can be considered as a "nonpolar hydrophobic tail." Further investigations of physicochemical properties and biological activity of the surfactant will be discussed in our next works.

\section{Funding}

This study was partially supported by the Ministry of Education and Science of Ukraine (State Budget Projects 0119U100232 and 0120U100431) and by the Slovak Academic Information Agency (National Scholarship Programme of the Slovak Republic, Grants ID 25718 and 30750).

\section{Acknowledgments}

This research has no acknowledgments.

\section{Conflicts of Interest}

The authors declare no conflict of interest. 


\section{References}

1. Boethling, R.S.; Lynch, D.G. Quaternary Ammonium Surfactants. In Detergents, de Oude, N.T., Ed. Springer Berlin Heidelberg: Berlin, Heidelberg, 1992. https://doi.org/10.1007/978-3-540-47108-0_3.

2. Bhadani, A.; Singh, S.; Sakai, H.; Abe, M. Synthesis and properties of heterocyclic cationic gemini surfactants. Encyclopedia of Biocolloid and Biointerface Science $2 \mathrm{~V}$ Set 2016, 539-553, https://doi.org/10.1002/9781119075691.ch43.

3. Pandya, S.J.; Kapitanov, I.V.; Usmani, Z.; Sahu, R.; Sinha, D.; Gathergood, N.; Ghosh, K.K.; Karpichev, Y. An example of green surfactant systems based on inherently biodegradable IL-derived amphiphilic oximes. J. Mol. Liq. 2020, 305, 112857, https://doi.org/10.1016/j.molliq.2020.112857.

4. Bhadani, A.; Kafle, A.; Koura, S.; Sakai, K.; Sakai, H.; Abe, M. Physicochemical Evaluation of Micellar Solution and Lyotropic Phases Formed by Self-Assembled Aggregates of Morpholinium Geminis. ACS Omega 2017, 2, 5324-5334, https://doi.org/10.1021/acsomega.7b00428.

5. Wang, X.P.; Xiao, H.B. Synthesis of Amide-Based Surfactant Inhibitor for Carbon Steel Corrosion Protection Electrochemical Analysis. International Journal of Electrochemical Science 2017, 12, 268-279, https://doi.org/10.20964/2017.01.14.

6. Hegazy, M.A.; Samy, R.M.; Labena, A.; Wadaan, M.A.M.; Hozzein, W.N. 4,4'-(((1E,5E)-pentane-1,5diylidene)bis(azanylylidene))bis(1-dodecylpyridin-1-ium) bromide as a novel corrosion inhibitor in an acidic solution (part I). Materials Science and Engineering: C 2020, 110, 110673, https://doi.org/10.1016/j.msec.2020.110673.

7. Deyab, M.A. Understanding the anti-corrosion mechanism and performance of ionic liquids in desalination, petroleum, pickling, de-scaling, and acid cleaning applications. J. Mol. Liq. 2020, 309, 113107, https://doi.org/10.1016/j.molliq.2020.113107.

8. Abdellaoui, O.; Skalli, M.K.; Haoudi, A.; Kandri Rodi, Y.; Arrousse, N.; Taleb, M.; Ghibate, R.; Senhaji, O. Study of the inhibition of corrosion of mild steel in a $1 \mathrm{M} \mathrm{HCl}$ solution by a new quaternary ammonium surfactant. Mor. J. Chem. 2021, 9, 44-56, https://doi.org/10.48317/IMIST.PRSM/morjchem-v9i1.21313.

9. Nesane, T.; Mnyakeni-Moleele, S.S.; Murulana, L.C. Exploration of synthesized quaternary ammonium ionic liquids as unharmful anti-corrosives for aluminium utilizing hydrochloric acid medium. Heliyon 2020, 6 , e04113, https://doi.org/10.1016/j.heliyon.2020.e04113.

10. Jadhav, M.; Kalhapure, R.S.; Rambharose, S.; Mocktar, C.; Govender, T. Synthesis, characterization and antibacterial activity of novel heterocyclic quaternary ammonium surfactants. Journal of Industrial and Engineering Chemistry 2017, 47, 405-414, http://dx.doi.org/10.1016/j.jiec.2016.12.013.

11. Maneedaeng, A.; Phoemboon, S.; Chanthasena, P.; Chudapongse, N. Synthesis, interfacial properties, and antimicrobial activity of a new cationic gemini surfactant. Korean J. Chem. Eng. 2018, 35, 2313-2320, https://doi.org/10.1007/s11814-018-0133-6.

12. Sapozhnikov, S.V.; Sabirova, A.E.; Shtyrlin, N.V.; Druk, A.Y.; Agafonova, M.N.; Chirkova, M.N.; Kazakova, R.R.; Grishaev, D.Y.; Nikishova, T.V.; Krylova, E.S.; Nikitina, E.V.; Kayumov, A.R.; Shtyrlin, Y.G. Design, synthesis, antibacterial activity and toxicity of novel quaternary ammonium compounds based on pyridoxine and fatty acids. Eur. J. Med. Chem. 2021, 211, 113100, https://doi.org/10.1016/j.ejmech.2020.113100.

13. Padnya, P.L.; Terenteva, O.S.; Akhmedov, A.A.; Iksanova, A.G.; Shtyrlin, N.V.; Nikitina, E.V.; Krylova, E.S.; Shtyrlin, Y.G.; Stoikov, I.I. Thiacalixarene based quaternary ammonium salts as promising antibacterial agents. Biorg. Med. Chem. 2021, 29, 115905, https://doi.org/10.1016/j.bmc.2020.115905.

14. Zeng, M.; Xu, J.; Luo, Q.; Hou, C.; Qiao, S.; Fu, S.; Fan, X.; Liu, J. Constructing antibacterial polymer nanocapsules based on pyridine quaternary ammonium salt. Materials Science and Engineering: C 2020, 108, 110383, https://doi.org/10.1016/j.msec.2019.110383.

15. Tiwari, S.K.; Wang, S.; Huang, Y.; Zhou, X.; Xu, H.H.K.; Ren, B.; Peng, X.; Weir, M.D.; Li, M.; Cheng, L. The antibacterial effects of quaternary ammonium salts in the simulated presence of inhibitors in root canals: a preliminary in-vitro study. Coatings 2020, 10, 181, https://doi.org/10.3390/coatings10020181.

16. Alkhalifa, S.; Jennings, M.C.; Granata, D.; Klein, M.; Wuest, W.M.; Minbiole, K.P.C.; Carnevale, V. Analysis of the Destabilization of Bacterial Membranes by Quaternary Ammonium Compounds: A Combined Experimental and Computational Study. ChemBioChem 2020, 21, 1510-1516, https://doi.org/10.1002/cbic.201900698. 
17. Ogilvie, B.H.; Solis-Leal, A.; Lopez, J.B.; Poole, B.D.; Robison, R.A.; Berges, B.K. Alcohol-free hand sanitizer and other quaternary ammonium disinfectants quickly and effectively inactivate SARS-CoV-2. J. Hosp. Infect. 2021, 108, 142-145, https://doi.org/10.1016/j.jhin.2020.11.023.

18. Hora, P.I.; Pati, S.G.; McNamara, P.J.; Arnold, W.A. Increased Use of Quaternary Ammonium Compounds during the SARS-CoV-2 Pandemic and Beyond: Consideration of Environmental Implications. Environmental Science \& Technology Letters 2020, 7, 622-631, https://doi.org/10.1021/acs.estlett.0c00437.

19. Schrank, C.L.; Minbiole, K.P.C.; Wuest, W.M. Are Quaternary Ammonium Compounds, the Workhorse Disinfectants, Effective against Severe Acute Respiratory Syndrome-Coronavirus-2? ACS Infectious Diseases 2020, 6, 1553-1557, https://doi.org/10.1021/acsinfecdis.0c00265.

20. Baker, N.; Williams, A.J.; Tropsha, A.; Ekins, S. Repurposing Quaternary Ammonium Compounds as Potential Treatments for COVID-19. Pharm. Res. 2020, 37, 104, https://doi.org/10.1007/s11095-020-028428 .

21. Nguyen, L.N.; Oh, S. Impacts of antiseptic cetylpyridinium chloride on microbiome and its removal efficiency in aerobic activated sludge. Int. Biodeterior. Biodegrad. 2019, 137, 23-29, https://doi.org/10.1016/j.ibiod.2018.11.006.

22. Timmer, N.; Gore, D.; Sanders, D.; Gouin, T.; Droge, S.T.J. Sorbent-modified biodegradation studies of the biocidal cationic surfactant cetylpyridinium chloride. Ecotoxicol. Environ. Saf. 2019, 182, 109417, https://doi.org/10.1016/j.ecoenv.2019.109417.

23. Paley, O. Cetylpyridinium chloride. Synlett 2014, 25, 599-600.

24. Fizer, M.M.; Slivka, M.V.; Mariychuk, R.T.; Fizer, O.I.; Korol, N.I.; Kryvoviaz, A.O.; Lendel, V.G. Theoretical Estimation of Toxicity of New Condensed Heterocyclic Cationic Surfactants. In Proceedings of 2019 International Council on Technologies of Environmental Protection (ICTEP), 23-25 Oct. 2019; 87-90, https://doi.org/10.1109/ICTEP48662.2019.8968972.

25. Fizer, M.M.; Slivka, M.V.; Lendel, V.G. Peculiarities of 4-methallyl-5-methallylamino-1,2,4-triazole-3thione halogenation. Chemistry of Heterocyclic Compounds 2019, 55, 478-480, https://doi.org/10.1007/s10593-019-02484-8.

26. Korol, N.; Slivka, M.; Fizer, M.; Baumer, V.; Lendel, V. Halo-heterocyclization of butenyl(prenyl)thioethers of 4,5-diphenyl-1,2,4-triazol-3-thiole into triazolo[5,1-b] [1,3]thiazinium systems: experimental and theoretical evolution. Monatshefte für Chemie - Chemical Monthly 2020, 151, 191-198, https://doi.org/10.1007/s00706-019-02545-w.

27. Slivka, M.; Korol, N.; Fizer, M.; Baumer, V.; Lendel, V. [1,3]Thiazolo[3,2-b][1,2,4]triazol-7-ium salts: synthesis, properties and structural studies. Heterocycl. Commun. 2018, 24, 197-203, https://doi.org/10.1515/hc-2018-0048.

28. Fizer, M.; Slivka, M.; Rusanov, E.; Turov, A.; Lendel, V. [1,3]Thiazolo[2',3':3,4][1,2,4]triazolo[1,5a]pyrimidines - A New Heterocyclic System Accessed via Bromocyclization. J. Heterocycl. Chem. 2015, 52 , 949-952, https://doi.org/10.1002/jhet.2073.

29. Stewart, J.J.P. MOPAC2016 version 16.060W, Stewart Comput. Chem. 2016. Availble online: http://OpenMOPAC.net.

30. Stewart, J.J.P. Optimization of parameters for semiempirical methods VI: more modifications to the NDDO approximations and re-optimization of parameters. J. Mol. Model. 2013, 19, 1-32, https://doi.org/10.1007/s00894-012-1667-x.

31. Jmol, An open-source Java viewer for chemical structures in 3D. Available online: http://www.jmol.org/.

32. Hoggarth, E. 251. Compounds related to thiosemicarbazide. Part II. 1-Benzoylthiosemicarbazides. Journal of the Chemical Society (Resumed) 1949, https://doi.org/10.1039/JR9490001163.

33. Fizer, M.; Slivka, M.; Korol, N.; Fizer, O. Identifying and explaining the regioselectivity of alkylation of 1,2,4-triazole-3-thiones using NMR, GIAO and DFT methods. J. Mol. Struct. 2021, 1223, 128973, https://doi.org/10.1016/j.molstruc.2020.128973.

34. Fizer, M. Methallyl isothiocyanate. Synlett 2013, 24, 2019-2020, https://doi.org/10.1055/s-0033-1339703.

35. Bevziuk, K.; Chebotarev, A.; Fizer, M.; Klochkova, A.; Pliuta, K.; Snigur, D. Protonation of Patented Blue $\mathrm{V}$ in aqueous solutions: theoretical and experimental studies. Journal of Chemical Sciences 2018, 130, 12, https://doi.org/10.1007/s12039-017-1411-2.

36. Fizer, O.; Fizer, M.; Sidey, V.; Studenyak, Y.; Mariychuk, R. Benchmark of different charges for prediction of the partitioning coefficient through the hydrophilic/lipophilic index. J. Mol. Model. 2018, 24, 141, https://doi.org/10.1007/s00894-018-3692-x. 